tion if I state that, though naturally not a small woman, her height being five feet five inches and a half, she weighed only four stone seven pounds, and I could easily make my thumb and forefinger meet round the thickest part of the calf of her leg. The curvature of the spine said to exist was a deceptive appearance produced by her excessive leanness, and the consequent unnaiural prominence of the spinous processes of the vertebræ. I could detect no organic disease of any kind. The appetite was entirely wanting, and she consumed hardly any food beyond a little milk, a few mouthfuls of bread, and the like. From the first the patient's improvement was steady and uniform. The way she put on flesh was marvellous, and one could almost see her fatten from day to day. Within ten days all her pains, neuralgia, and backache, had gone, and have never been heard of since, and by that time we had also got rid of all her little pillows and other invalid appliances.

It may be of interest, as showing what this system is capable of, if I copy her food diary on the tenth day after her treatment was begun; and all this, this bedridden patient, who had lived on starvation diet for twenty years, not only consumed with relish, but perfectly assimilated :-

6 A.M. : Ten ounces of raw meat soup. 7 A.M. : Cup of black coffee. 8 A.M. : A plate of oatmeal porridge with a gill of cream, a boiled egg, three slices of bread-and-butter, and cocoa. 11 A.M. : Ten ounces of milk. 2 P.M. : Half a pound of rumpsteak, potatoes, cauliflower, a savoury omelette, and ten ounces of milk. 4 P.M. : Ten ounces of milk and three slices of bread-and-butter. 6 P.M. : A cup of gravy soup. 8 A.M. : A fried sole, roast mutton (three large slices), French beans, potatoes, stewed fruit and cream, and ten ounces of milk. 11 P.M. : Ten ounces of raw meat soup.

The same scale of diet was continued during the whole treatment, and, from first to last, never produced the slightest dyspeptic symptoms, and was consumed with relish and appetite. At the end of six weeks from the day I first saw her she weighed 7 st. $8 \mathrm{lb}$. - that is a gain of $3 \mathrm{st} .1 \mathrm{lb}$. It will suffice to indicate her improvement if $I$ say that in eight weeks from the commencement of treatment she was dressed, sitting up to meals, able to walk up and downstairs with an arm and a stick, and had also walked in the same way in the park. Considering how completely atrophied her muscles were from twenty years' entire disuse, this was much more than I had ventured to hope. She has now left with her nurse for Natal, and $I$ have no doubt that she will return from her travels with her cure perfected.

(To be concluded.)

\section{ON HIGH LOCAL TEMPERATURES.}

\section{BY WILLIAM SQUIRE, M.D., F.R.C.P.}

THE excessive temperatures in non-fatal cases, from time to time recorded of late, have been found only at very limited areas, and have mostly had no relation to the general body temperature when that has been obtained in a satisfactory manner. Many of the accidents which might vitiate these exceptionally high readings have long been demonstrated and discussed; now that, in two instances, intentional deceptions have been detected and exposed, it would be well if the recorders of some of the more paradoxical observations would review their experience by the light of those recent examples, and inform us in what circumstances they may correspond or differ. A long attention to surface thermometry, while revealing numerous sources of error, such as undue or unequal warming or covering of the part to be examined, shows some very real and important differences; these deserve careful note, and will some day admit of useful generalisations. As a provisional deduction it may be stated that these natural variations seldom exceed by as much as $4^{\circ}$ or $5^{\circ}$ that of a corresponding part of the surface, and are still more rarely even a degree above the internal or general temperature of the body. How largely the reverse of this may be possible is well known. Collapse may set in from an intense fever at its height, and the limbs be algide while the head and body burn. During scarlet fever the temperature in recto has been $105^{\circ}$, and at the same time only $97^{\circ}$ in the skin of the abdomen or in its folds. In the axilla an accurate surface thermometer has marked $103^{\circ}$ on the thoracic side and only $98^{\circ}$ on its brachial aspect; this was found in acute pulmonary congestion near the close oi chronic lung disease. In right hemiplegia of two multh: standing the paralysed arm and the left side of the face were two and three degrees higher than the parts unaffected; the surface temperature of the head over the side corresponding to the supposed seat of cerebral lesion being $11^{\circ}$ lower than the opposite side. From some obscure affection of the cer. vical sympathetic, probably, an active man thirty years old has a persistent flush on the left side of the face. This is worse when he is heated; on any little exertion or excitement that side of the face and forehead are bedewed with per. spiration ; the temperature, while he is at rest in a cool room, is $4^{\circ}$ higher on the left temple than on the right; it was $90^{\circ}$ on the right and $94^{\circ}$ on the left temple in the morning of a cold day. A difference of half a degree is frequently found on the two sides of the forehead. The range in health at various times of the day and under varying conditions is usually from $92^{\circ}$ to $96^{\circ}$, but the difference between the two sides is seldom as much as half a degree, and the left temple is rather more often the higher than the right. There are some conditions of hemi-anæsthesia and of hyperæsthesia where the symptoms more or less suddenly change from side to side that have a like curious variation in temperature. These cases have a variation of only two or three degrees, and are not limited to hysterical subjects. A temperate man near the age of forty had to lay up for three weeks for pyelitis and renal irritation, with severe headache, chiefly on the left side; in early convalescence with normal tempera ture in ore the right temple was $964^{\circ}$, the lest $94^{\circ}$, and it was noted as curious that the temperature of the right axilla was only $976^{\circ}$, while the left was $98 \cdot 2^{\circ}$. The following week, during a relapse, the temperature at noon in ore was $100.6^{\circ}$, that of the right axilla $101 \cdot 6^{\circ}$, of the left $100 \cdot 3^{\circ}$, both temples close on $98^{\circ}$. At night the general temperature was $101^{\circ}$. His temperature on the next day at noon was $98^{\circ} 6^{\circ}$ in ore, $98.8^{\circ}$ in recto, right axilla $982^{\circ}$, left $97.4^{\circ}$, right temple $94^{\circ}$ left temple $94 \cdot 5^{\circ}$. Urine pale, sp. gr. 1016, slightly turbid, mucous deposit, a trace of albumen. Pulse 80, respiration 18. Before recovery was complete headaches with loss of sleep recurred with shifting of the increase of temperature from the right axilla and right side of the trunk to the left side, and of the higher head temperature from the left to right, and vice "ersa, more than once. In a contribution of mine on "Surface Temperatures" to one of the medical periodicals in the early part of last year, Mr. J. W. Teale's case of abnormal high temperature is referred to as one of local disturbance. It would be more satisfactory to know, and if Mr. Teale still has notes of the case he may be induced to give some further details, how far any general disturbance of temperature was noted, and in what parts of the body; also whether any evidence of increased ustion, as by high colour or specific gravity of the urine, or wasting occurred. Any further records of the pulse and respiration rate would be interesting, especially if there was a tendency to hysteria; also the state of the mouth and tongue and the general condition of the surface. Was the thermometer always held in the axilla and surface, and watched during the observation; and, further, were hot bottles in use? Finally, was the patient at the outset liable to a suspicion of deception, and, a circumstance perhaps of more importance to report now, what has been the subsequent medical his. tory of the patient, and what the present state?

Orchard-street, Portman-square, W.

\section{CASES ILLUSTRATING THE SURGERY OF CHILDREN.}

BY G. A. WRIGHT, F.R.C.S.,

SURGEON TO THE HOSPITAL FOR CHILDREN, PENDLEBURY.

CASE 1. Pulpy disease of the knee; erasion.-E. Naged thirteen, was first attacked with pain and swelling of the right knee in September, 1879. She was admitted into the Children's Hospital, Pendlebury, in May, 1880, for pulpy synovitis of the knee. At this time there was some effusion into the joint. She was treated by rest on a back splint and Scott's dressing, and discharged improved at the end of June. On Dec. 2nd, 1880, she was readmitted with advanced pulpy disease. There were swelling and tenderness at the outer and inner sides of the 